\title{
The Problem of Many Hands: Climate Change as an Example
}

\author{
Ibo van de Poel · Jessica Nihlén Fahlquist • \\ Neelke Doorn · Sjoerd Zwart • Lambèr Royakkers
}

Received: 5 July 2010/Accepted: 17 April 2011/Published online: 1 May 2011

(C) The Author(s) 2011. This article is published with open access at Springerlink.com

\begin{abstract}
In some situations in which undesirable collective effects occur, it is very hard, if not impossible, to hold any individual reasonably responsible. Such a situation may be referred to as the problem of many hands. In this paper we investigate how the problem of many hands can best be understood and why, and when, it exactly constitutes a problem. After analyzing climate change as an example, we propose to define the problem of many hands as the occurrence of a gap in the distribution of responsibility that may be considered morally problematic. Whether a gap is morally problematic, we suggest, depends on the reasons why responsibility is distributed. This, in turn, depends, at least in part, on the sense of responsibility employed, a main distinction being that between backward-looking and forward-looking responsibility.
\end{abstract}

Keywords Responsibility · Technology · Engineering ·

Problem of many hands - Collective responsibility · Climate change

\section{Introduction}

When engineering structures fail or an engineering disaster occurs, the question who is to be held responsible is often asked. However, in complex engineering projects,

I. van de Poel $(\bowtie) \cdot$ J. Nihlén Fahlquist $\cdot$ N. Doorn $\cdot$ S. Zwart

Department of Technology, Policy and Management, Technical University Delft,

P.O. Box 5015, 2600 GA Delft, The Netherlands

e-mail: I.R.vandepoel@tudelft.nl

\section{S. Zwart · L. Royakkers}

Department of Technology Management, Eindhoven University of Technology,

P.O. Box 513, 5600 MB Eindhoven, The Netherlands

J. Nihlén Fahlquist

Philosophy, Royal Institute of Technology, Teknikringen 78B, SE-100 44 Stockholm, Sweden 
it is often quite difficult to pinpoint responsibility. In a review of a hundred shipping accidents, Wagenaar and Groenewegen conclude: "Accidents appear to be the result of highly complex coincidences which could rarely be foreseen by the people involved. The unpredictability is due to the large number of causes and by the spread of the information over the participants" (Wagenaar and Groenewegen 1987: 596). Since the ability to foresee undesirable consequences is usually seen as a condition for responsibility, this raises doubts whether it is reasonable to hold someone responsible for the accident that occurred.

The phenomenon that, due to the complexity of the situation and the number of actors involved, it is impossible or at least very difficult to hold someone reasonably responsible is sometimes referred to as the problem of many hands. Dennis Thompson, who was probably the first to use the notion "the problem of many hands" in an article about the responsibility of public officials, describes it as follows: "Because many different officials contribute in many ways to decisions and policies of government, it is difficult even in principle to identify who is morally responsible for political outcomes" (Thompson 1980: 905). In a more recent article, Helen Nissenbaum discusses the problem of many hands as one of the barriers for attributing accountability in what she calls a 'computerized society.' Some of the barriers she describes are, however, more generally characteristic for modern technology and engineering. She characterizes the problem of many hands as follows: "Where a mishap is the work of "many hands," it may not be obvious who is to blame because frequently its most salient and immediate causal antecedents do not converge with its locus of decision-making. The conditions for blame, therefore, are not satisfied in a way normally satisfied when a single individual is held blameworthy for a harm" (Nissenbaum 1996: 29).

Nissenbaum thus attributes the problem of many hands to the difficulty of holding any individual responsible because the different traditional preconditions for responsibility, like intent, knowledge, and freedom of action are distributed over many different individuals and none of them might meet all the conditions. According to her, "the upshot is that victims and those who represent them are left without knowing at whom to point a finger. It may not be clear even to the members of the collective itself who is accountable" (Nissenbaum 1996: 29). However, "we should not mistakenly conclude from the observation that accountability is obscured due to collective action that no one is, or ought to have been, accountable" (Nissenbaum 1996: 32, emphasis in original).

It remains unclear, however, whether Nissenbaum believes that it is always problematic if no one can reasonably be held responsible or that it is only problematic in some specific cases. Bovens (1998: 47) has made an interesting suggestion in this respect; he suggests that the problem of many hands occurs if a collective is responsible for an undesirable outcome but none of the individuals in the collective is responsible. Like Bovens, we believe that the problem of many hands can be understood in terms of a morally problematic gap in the distribution of responsibility among the members of a collective. We are, however, not so sure whether one needs the condition of the collective being responsible for the problem of many hands to occur.

In order to improve upon Bovens' characterization of the problem of many hands, we will discuss and analyze a case in detail: responsibility for climate change. We 
think climate change is a typical example of a many hands problem because it is a phenomenon that is very complex, in which a large number of individuals are causally involved, but in which the role of individuals in isolation is rather small. ${ }^{1}$ In such situations, it is usually very difficult to pinpoint individual responsibility. Climate change is also a good example of how technology might contribute to the occurrence of the problem of many hands because technology obviously plays a major role in climate change, both as cause and as a possible remedy.

Our purpose in analyzing the case of climate change is not to take a position in the debate about who exactly is responsible for climate change (if anyone is). Rather, we want to show that on some interpretations it would be reasonable to maintain that nobody is (in some sense) responsible for climate change and, therefore, the case may be seen as an example of the problem of many hands. We will then use this interpretation of the case as a basis for developing a more precise definition of the problem of many hands.

Typically, in cases like the climate change example different meanings of the term 'responsibility' are at play. We, therefore, start with setting out some of the main distinctions in how the notion of responsibility is used. We will then focus on responsibility-as-blameworthiness, and the conditions under which it applies to individuals, as this is usually the main sense of responsibility focused on in discussions about the problem of many hands. After discussing climate change as an example, we look at what this example implies for our understanding of the problem of many hands and propose a redefinition of it.

\section{Senses of Responsibility}

The notion of responsibility has different meanings. Hart was the first one to distinguish different senses of responsibility (1968: 210-237). He mentions four main senses: role-responsibility, causal-responsibility, liability-responsibility and capacity-responsibility. In his contribution to this special issue, Michael Davis distinguishes nine senses of responsibility. Some of the senses of responsibility distinguished by Hart and Davis are merely descriptive. Our focus in this contribution is on moral responsibility, i.e. responsibility that is attributed on moral grounds rather than on basis of the law or organizational rules. When focusing on moral responsibility, a main distinction is that between backward-looking responsibilities for something that has happened in the past and forward-looking responsibility for things that have not yet occurred (cf. Nihlén Fahlquist 2006; Van de Poel forthcoming).

Most of the philosophical literature on responsibility tends to focus on backwardlooking responsibility and often understands backward-looking responsibility in terms of reactive attitudes (e.g. Wallace 1994; Strawson 1962). That is to say, if it is reasonable to hold someone responsible for something, it is considered reasonable to have certain reactive attitudes to that person in respect of the thing for which the

\footnotetext{
1 We are assuming here that climate change is at least for a considerable part caused by humans; whether this assumption is actually true will not be relevant for the arguments discussed.
} 
person is held responsible. Although such reactive attitudes may take different forms, the most common denominator seems to be blame. We will, therefore, call this sense of responsibility responsibility-as-blameworthiness.

It should be noted that responsibility-as-blameworthiness is not the only sense of backward-looking moral responsibility. Two other main senses are responsibilityas-accountability and responsibility-as-liability (Davis forthcoming; Van de Poel forthcoming). We will understand accountability basically in the sense of being obliged to account for one's actions and their outcomes. Moral liability is related to obligations to victims of one's action, like being obliged to pay damages or to remedy an injustice caused.

Forward-looking responsibility is often understood in relation to institutional roles or tasks. It should be noted, however, that one might be morally responsible in a forward-looking sense in the absence of explicit roles or tasks. We will distinguish here between forward-looking responsibility-as-obligation and forward-looking responsibility-as-virtue. If one is responsible-as-obligation, one has to see to it that a certain desirable state-of-affairs obtains, although one is free in how this state-ofaffairs is to be brought about (Goodin 1995; Van de Poel forthcoming). Whereas responsibility-as-obligation can be, but is not necessarily voluntarily assumed, responsibility-as-virtue is something which agents take upon themselves. ${ }^{2}$ It might also be understood as not primarily referring to state-of-affairs that need to be achieved but rather to character traits, for example caring relationship to others (Nihlén Fahlquist 2009b).

It might be argued that these different senses of responsibility are not mutually exclusive but are rather different aspects of one and the same notion of responsibility. Still it is important to distinguish between them to avoid terminological and conceptual confusion. In most cases, discussions about the problem of many hands focus on responsibility-as-blameworthiness. ${ }^{3}$ We will therefore start with a brief overview of the conditions for responsibility-as-blameworthiness that have been discussed in the literature, as prelude to the climate change example. There is, however, no reason why we could not speak of a problem of many hands with respect to, for example, responsibility-as-obligation. We will in fact argue, in the final section, that distinguishing between the different senses of responsibility enriches our understanding why, and when, exactly the problem of many hands may be considered morally problematic.

\section{Responsibility-as-Blameworthiness}

Following the literature on responsibility, we will assume that an agent can reasonably be held responsible-as-blameworthy if and only if certain conditions are

\footnotetext{
${ }^{2}$ Whether and to what extent character traits are voluntary is a question philosophers have different opinions about (cf. Audi 1991).

3 The quotes in the introduction from Nissenbaum refer both to blameworthiness and accountability. She seems, however, not to clearly distinguish between the two, and the sense of responsibility she is using seems closest to what we call responsibility-as-blameworthiness. The conditions for accountability she discusses are also similar to the conditions for blameworthiness we discuss below.
} 
fulfilled. The conditions of responsibility have been discussed throughout the history of philosophy and there are countless different views on the relevance and priority of them. Still we think a common framework can be defined that contains the main types of conditions mentioned in the literature. We will not take a stance as to whether all conditions are equally important or the exact content of the conditions. The point of this discussion is merely to provide a framework that helps to discuss when it is reasonable to hold someone responsible.

Below, we will argue that the following conditions together capture the general notion of when it is reasonable to hold an agent morally responsible-asblameworthy:

(1) Capacity

(2) Causality

(3) Knowledge

(4) Freedom

(5) Wrong-doing

The first condition, 'capacity', is closely related to the question of moral agency. Philosophers and non-philosophers alike commonly exempt some groups of human beings from responsibility, for example children and people with mental disorders, because they lack the capacity to act responsibly (Wallace 1994; cf. Austin 1956-1957). In the literature, there has been discussion whether animals or even machines should be awarded moral agency and hence should be eligible for normative assessment, although few actually defend such positions (Shapiro 2006; Johnson 2006). The discussion of whether it is appropriate to ascribe responsibility to collective entities also focuses on this condition. It is essentially a question of whether collectives are eligible for normative assessment. ${ }^{4}$

The second condition is that the agent in question actually caused that for which she is being held responsible-as-blameworthy. We call this the condition of causality. Some theorists treat causality as the condition for moral responsibility: if an agent causes harm to another she is responsible for that even if she could not have foreseen it or was not acting voluntarily. This is so because either there is an individual as well as societal interest to hold everyone who caused harm responsible or because people feel justified regret when they cause harm regardless of why or how hey caused harm (Honoré 1999; Williams 1999; Zandvoort 2000; Vedder 2001).

Most people do not ascribe responsibility to an agent unless she appears to have contributed causally to that for which she is held responsible. The question is what sense of causation one should adopt, and how strong the causal link should be in order for someone to reasonably be held responsible. Similarly, causation is not the only condition most people refer to when holding others responsible.

Aristotle argued that an agent is not responsible-as-blameworthy if the action was performed involuntarily. To be voluntary, an action should not have been performed

\footnotetext{
4 A normative assessment does not have to be moral. It could be aesthetic or prudential (there are also epistemic norms and norms of logic), but the most common one in the context we are discussing might be moral (see Audi 1991).
} 
under compulsion or ignorance. We call the latter the knowledge condition (condition 3). Like the causality condition, the knowledge condition is much more complicated in the technological age than it was at the time of Aristotle's analysis. One could argue that, for example, engineers are only responsible for what they actually know or are aware of. However, this neglects the reasonable notion that engineers also have a duty to know or find out some things. This duty is entailed by their role as engineers, as professionals that have knowledge and experience that goes beyond the knowledge and experience of laypeople. The knowledge condition then has a normative aspect, it relates to what people should know or can reasonably be expected to know. People are only excused by non-culpable ignorance.

The second excusing condition has been called the freedom condition (our condition 4) or the control condition. If the agent was acting under compulsion she is not responsible (Aristotle 2000: Book 3). If an agent A is compelled to do X, it is not reasonable to hold her responsible for $\mathrm{X}$ or for the consequences of $\mathrm{X}$. However, regarding the questions what constitutes coercion and when actions can reasonably be viewed as free, the disagreement is considerable. The extensive discussion between compatibilists and incompatibilists in the metaphysical debate about 'responsibility and free will' essentially concerns this condition. The focal point of that debate is whether it is reasonable to hold individuals responsible if human beings are causally determined. Some philosophers in this debate argue that the kind of control necessary for responsibility requires that we have alternatives (cf. van Inwagen 1983; Ginet 2006; Widerker 2005; Copp 2006) whereas others disagree (French et al. 2005; Frankfurt 1969; Widerker and McKenna 2006).

Thus, there is extensive discussion on the condition of freedom, its meaning and scope. However, few would argue that if an agent performs an act under compulsion, she is responsible-as-blameworthy; disagreement concerns when an act can be said to be free.

When we hold agents responsible-as-blameworthy it is usually the case that some harm has occurred or some norm has been transgressed. ${ }^{5}$ An agent has done something that is perceived as wrong (condition 5) and therefore she is blameworthy for that thing, given that she did it voluntarily and knowingly (Smiley 1992). Clearly, what counts as wrong-doing is at the core of the discipline of ethics, and utilitarian, deontological and virtue ethics give different answers to this question. However, what is important in this context is that there is enough agreement that when we hold an agent responsible it is partly because the agent is perceived to have done something wrong, regardless of whether the argument is based on utilitarian, deontological, virtue ethics or based on some other set of ethical principles or norms.

As we have seen, there is disagreement on which of the conditions are most important and how each condition should be interpreted. However, for our purpose in this paper, we only need to agree on the following issues: (a) there are a number of conditions for reasonably holding an agent responsible and (b) although there is

\footnotetext{
${ }^{5}$ Of course sometimes we hold agents responsible when they have done something good or praiseworthy. However, when discussing responsibility-as-blameworthiness, we are interested in the negative outcomes of engineering projects and how to prevent these.
} 
disagreement on the exact meaning and relevance of these conditions, there is considerable agreement that a reasonable ascription of moral responsibility requires that the agent was eligible for normative assessment, caused the unwanted outcome, did it knowingly and freely (to an adequate extent), and that the agent's action constituted wrong-doing according to some normative framework.

\section{Climate Change}

We will now look at climate change as an example of a situation in which the problem of many hands occurs, or at least seems to occur. Several publications have appeared recently on responsibility for climate change (e.g. Caney 2005; Jamieson 2010; Miller forthcoming; Sinnott-Armstrong 2005; Vanderheiden forthcoming). We will be mainly focusing on two contributions: an article by Baylor Johnson in Environmental Values (Johnson 2003) on moral obligations in a tragedy of the commons and a book contribution by Walter Sinnott-Armstrong (Sinnott-Armstrong 2005). Although both talk primarily about 'moral obligations' rather than 'moral responsibility,' their arguments are directly relevant for the attribution of individual moral responsibility for climate change, as we will see in the next section. We will reconstruct their arguments in terms of the conditions for individual moral responsibility discussed above.

As we saw in the previous section, the attribution of individual moral responsibility usually requires that five conditions are met: capacity, causality, knowledge, freedom and wrong-doing. In relation to responsibility for climate change, capacity is not an issue. Most individuals that we possibly want to hold responsible for climate change have the right capacities to qualify as moral agents. Causality is, however, a more contentious issue. Sinnott-Armstrong asks whether I can be reasonably held responsible for global warming if I drive for fun on Sundays, so causally contributing, albeit it in a very small degree, to global warming. He starts with noting that "my individual act is neither necessary nor sufficient for global warming" (Sinnott-Armstrong 2005: 289). As he admits, however, there are "special circumstances in which an act causes harm without being either necessary or sufficient for the harm" (Sinnott-Armstrong 2005: 289). However, he maintains, that in such cases the act, to be properly called a cause either needs to be intentionally aimed at the harm or to be 'unusual.' As he explains, we do not usually call oxygen a cause of fire because oxygen is in normal circumstances present, we might call the striking of a match the cause because it is unusual (Sinnott-Armstrong 2005: 290). He concludes that "we should not hold people responsible for harms by calling their acts causes of harm when their acts are not at all unusual, assuming that they did not intend the harm" (Sinnott-Armstrong 2005: 290). ${ }^{6}$ Since driving for fun on Sunday is, according to Sinnot-Armstrong, neither unusual nor does it do intentional harm, it cannot be considered a cause of global warming. He also argues

\footnotetext{
${ }^{6}$ It should be noted that Sinnott-Armstrong is not arguing that usual things are necessarily morally acceptable; rather, he thinks that they cannot qualify as cause. Sinnott-Amstrong's contrast between usual and unusual events is closely related to Mackie's notion of causal field (Mackie 1980: 35) and to the distinction between abnormal and normal conditions of Hart and Honoré (1985: 33).
} 
that another argument leads to the same conclusion: "Greenhouse gases (such as carbon dioxide and water vapour) are perfectly fine in small quantities. They help plants grow. The problem emerges only when there is too much of them. But my joyride by itself does not cause the massive quantities that are harmful" (SinnottArmstrong 2005: 290). ${ }^{7}$

The third condition for responsibility is knowledge. Johnson and SinnottArmstrong do no refer to this condition, but Dale Jamieson mentions it in an article on responsibility and climate change in this journal:

According to a recent Rasmussen Report, $44 \%$ of American voters say that climate change is primarily caused by long-term planetary trends rather than human activity....It could be argued that these Americans are culpable in their ignorance of the relation between human action and climate change, but when prominent public figures are climate change deniers and science education is so obviously inadequate it is difficult to make this case (Jamieson 2010: 437, footnote 11$){ }^{8}$

Whether global warming is really a case of excusable ignorance seems debatable, but it is telling that even some philosophers think it might be.

Also the freedom condition is relevant with respect to responsibility for climate change. Some contributions to global warming might be considered unavoidable or involuntary, like breathing, which produces carbon dioxide. Usually discussions about responsibility for climate change, therefore, focus on luxury emissions rather than on survival emissions (although the line between both may not always be clear). But even in the case of luxury emissions, absence of coercion may not be enough to call an act voluntary. One of us, Jessica Nihlén Fahlquist (2009a), has argued that people should have reasonable alternatives in order to be reasonably held responsible for environmental problems. What alternatives are reasonable might thereby depend on contextual and situational features; alternatives that are reasonable for rich people may not be reasonable for less prosperous people.

Let us, finally, look at the wrong-doing condition. This condition is the main target of both Sinnott-Armstrong and Johnson. Sinnott-Armstrong discusses a large number of possible moral principles on basis of which individuals may have a moral obligation to avoid global warming as individuals; he rejects, however, all of them. Also Johnson argues that, despite what many people believe, individuals do not have a moral obligation to restrain themselves to a sustainable level of consumption in a tragedy of the commons. The main reasons for her to believe that such an obligation is absent seem to be that she believes:

\footnotetext{
7 Again this seems best understood as an argument about causality rather than about what is moral or immoral. Nevertheless, the argument clearly raises issues about moral obligations in a tragedy of the commons, a topic that will be discussed below.

${ }^{8}$ According to an even more recent Rasmussen Report, the percentage blaming planetary trends is up to 47\% in December 2010. See: http://www.rasmussenreports.com/public_content/politics/current_events/ environment_energy/41_now_say_global_warming_is_caused_by_human_activity_more_say_planetary_ trends Accessed 4 February 2011.
} 
(1) That it is not reasonable to expect that unilateral restrictions of consumption by individuals are likely to be effective in avoiding a tragedy of the commons.

(2) That unilaterally restricting one's consumption would entail a sacrifice and that "a prima facie moral obligation can be overridden by the sacrifice it would entail" (Johnson 2003: 281), and

(3) That there is "nothing wrong with any one person's use of the commons" in a typical tragedy of the commons because no "one person's use is large enough to harm the commons" (Johnson 2003: 277).

Crucial in Johnson's argument is the absence of an effective collective agreement. As she argues:

There is a vast difference between (a) free riding or otherwise failing to live up to an existing (and functioning) collective agreement that produces benefits, and (b) refusing to act unilaterally in the way one would like to see universalised when that is costly to oneself and cannot reasonably be expected to produce the outcome whose pursuit justifies one's action. The former is a paradigm of unethical behaviour....By contrast, in the absence of the collective agreement that would give one's restraint a chance of securing its object, there is no point and no obligation to make the sacrifice that restraint entails. (Johnson 2003: 282)

It should be noted that Johnson is not arguing here that we should not strive for collective agreements; in fact she believes that there is a genuine moral obligation for individuals to do so as we will see in the next section. Rather, her argument should be understood in terms of the moral obligations that individuals have if a collective agreement is de facto absent.

Johnson's focus is on moral obligations in a tragedy of the commons and not on climate change, and while there seem to be good reasons to conceive of climate change as a tragedy of the commons, one might wonder whether in the case of climate change there is an effective collective agreement that would create moral obligations for individual citizens. The best candidate is perhaps the Kyoto Protocol under which a large number of industrialised countries have committed themselves to a reduction in greenhouse gases. It may, however, be doubted whether the Kyoto Protocol creates moral obligations for individual citizens. First, the Protocol is an agreement between nations, or their governments, and it might be argued that unless national governments have translated the Kyoto reduction goals into effective national policy, citizens of those countries have no individual moral obligations to reduce greenhouse gases unilaterally. This is not to deny that governments have a moral obligation to device such national policies; the argument only states that in the actual absence of such policies, individual citizens may not have moral obligations to restrict their own emissions. Second, the US is not a party to the Kyoto Protocol and, hence, it seems that, at least on Johnson's argument, the treaty cannot create moral obligations for US citizens. Again, the point is not that the US government does not have a moral obligation to sign the Kyoto Protocol, but that individual citizens in the US can have no moral obligations on basis of the protocol as long as the US is not actually committed to it. 


\section{Attributing Responsibility for Climate Change}

As we have seen both Sinnott-Armstrong and Johnson believe that citizens do not have a moral obligation to avoid global warming as individuals. Although it might be argued that not all moral obligations entail forward-looking responsibilities, since some might be better conceived as duties (Van de Poel forthcoming), it seems clear that without a moral obligation there cannot be a forward-looking responsibility-as-moral-obligation. ${ }^{9}$ So both Sinnott-Armstrong and Johnson seem to subscribe to the following statement:

(1) Individuals do not have a forward-looking responsibility-as-obligation to unilaterally avoid global warming.

We have added the word 'unilaterally' here because both Sinnott-Armstrong and Johnson believe that individuals as citizens have a forward-looking responsibilityas-moral-obligation to see to it that their governments take adequate measures against global warming. Sinnott-Armstrong, for example, writes that individuals have certain "real moral obligations, which are to get governments to do their job to prevent the disaster of excessive global warming" (Sinnott-Armstrong 2005: 304). Similarly, Johnson states that citizens have an obligation "to 'do the right thing' without waiting for others. 'The right thing' is not, however, a fruitless, unilateral reduction in one's use of the commons, but an attempt to promote an effective collective agreement that will coordinate reductions in commons use and therefore avert aggregate harm" (Johnson 2003: 284). Both thus subscribe to:

(2) Individuals have a forward-looking responsibility-as-obligation to see to it that collective agreements are achieved, which effectively abate global warming.

Both also maintain that individuals can voluntarily take the responsibility to unilaterally reduce their reductions, although they are not obliged to do so. Johnson, for example, argues that "individual reductions are surely morally permissible and perhaps even praiseworthy as supererogatory acts" (Johnson 2003: 285). And Sinnott-Armstrong says that "it is still morally better or morally ideal for individuals not to waste gas. We can and should praise those who save fuel" (Sinnott-Armstrong 2005: 303). This seems to refer to what we have earlier introduced as responsibility-as-virtue and both therefore subscribe to:

(3) Individuals can voluntarily assume a forward-looking responsibility-as-virtue to unilaterally abate global warming and it is morally praiseworthy if they do so.

What does the above discussion imply for the attribution of backward-looking responsibility-as-blameworthiness to individuals? As we have seen, a reasonable attribution of responsibility-as-blameworthiness requires wrong-doing, and, hence, a breach of some moral obligation. Now obviously statement 1 denies that people's

\footnotetext{
${ }^{9}$ Moral obligations refer to the fifth condition (wrong-doing) discussed above for responsibility-asblameworthiness. It should be noted that for responsibility-as-moral-obligation somewhat different conditions apply; see also the discussion in the final section of the paper.
} 
direct individual contribution to global warming amounts to wrong-doing. ${ }^{10}$ Hence, direct individual contributions cannot be the ground for proper blame. Statement 3 says people can assume responsibility for their individual contributions, and maybe if they have actually done so and have not lived up to this assumed responsibility they may be blamed. However, statement 3 leaves open the possibility that nobody actually assumes this individual responsibility and in that case nobody can be reasonably blamed for their direct contribution to global warming as assuming responsibility-as-virtue, at least according to 3 , is voluntary and not obligatory.

The best ground for possible individual blameworthiness then seems to be the moral obligation worded in 2 . Not living up to this responsibility may be said to contribute indirectly to global warming. Below we will suggest, however, that it might be possible to discharge the individual responsibility worded in 2 properly without an effective collective agreement being achieved. One reason why this is possible is that a collective agreement may be achieved that turns out to be ineffective for reasons that could not have been reasonably foreseen. This would be a case of inculpable ignorance and, as we have seen, this is an excusing condition for blameworthiness.

Another possibility is that a collective agreement is not achieved. In a democracy, collective agreement typically depends on majority decision-making and even if some citizens have properly fulfilled their responsibility worded in 2 they may be outnumbered by people who oppose an effective collective agreement. In such cases, this second group of individuals may be blameworthy. Pettit (2007) has, however, suggested that due to so-called voting paradoxes or discursive dilemmas a collective decision may be made that is actually supported by none of the individual voters. He has argued that in such cases none of the individual voters can be held responsible for the decision made and that only the group, as collective, can be properly held responsible. Pettit's argument has been contested (e.g. Miller 2007; Hindriks 2009; Braham and van Hees 2010) but if he is right it shows that possibly no individual might be properly held responsible for the failure to achieve a collective agreement to effectively abate climate change.

These two arguments related to 2 then suggest the following:

(4) It is possible that no individual can be reasonably held backward-looking responsible-as-blameworthy for the failure to achieve a collective agreement to effectively abate climate change.

Assuming that statement 1 and 2 cover the only relevant moral obligations in this case, the result is:

(5) It is possible that no individuals can be reasonably held backward-looking responsible-as-blameworthy for global warming.

This result suggests that the problem of many hands might indeed occur with respect to climate change, in the sense, that, indeed, it might well be that nobody can reasonably be held responsible-as-blameworthy for climate change (and its

\footnotetext{
${ }^{10}$ Here we are assuming that there is no effective collective agreement in place. Cf. our discussion above.
} 
consequences). Of course, this result depends on various assumptions. The strongest assumption is perhaps the one worded in statement 1 above. This statement has, as we have seen, been defended in detail by both Sinnott-Armstrong and Johnson. We think, however, that 5 might be established even if 1 were false. One reason for that is that wrong-doing, the condition for responsibility-as-blameworthiness to which 1 refers, is only one of the conditions for responsibility-as-blameworthiness. As we have seen also the four other conditions (capacity, causality, knowledge and freedom) have to apply. While capacity is usually not at issue in debates about responsibility for climate change, each of the other conditions has been mentioned by at least some philosophers as a possible reason why citizens cannot reasonably be held responsible-as-blameworthy for climate change.

It should further be noted that in the absence of a collective agreement, and hence the absence of effective coordination between individuals, it is very difficult for individuals to decide what individual restrains they should apply to collectively avoid climate change (or limit it to a manageable degree). One might argue that each individual should do what is reasonably, possible for him/her. It is, however, far from clear whether, if every individual lived by such a moral obligation in isolation, the collective effect would be the prevention of climate change. Rather it seems likely that effectively abating global warming requires coordinated efforts. ${ }^{11}$ So even if individuals do have a moral obligation to unilaterally contribute (contra Sinnott-Armstrong and Johnson) to avoiding global warming and even if they did live by that obligation, climate change may not be prevented (or limited to a manageable degree). Again it seems possible to establish 5, now because individuals properly fulfilled their individual responsibility although the undesirable collective outcome is not prevented.

Apart from the above arguments, it seems telling that in cases like this we can reasonably disagree whether anyone can be held responsible. If the problem of many hands is not only a philosophical problem but also a practical problem, as is often suggested, reasonable disagreement about who can be held responsible might already cause the problem to occur in practical contexts. To see how serious this is we first need to consider in more detail what the problem of many hands exactly is and why it is problematic, a task to which we now turn.

\section{The Problem of Many Hands}

The climate change example suggests that it is sometimes very difficult, if not impossible, to hold anyone responsible for a collective harm. It, therefore, seems a typical example of the problem of many hands. Of course, the arguments provided by Sinnott-Armstrong and Johnson, and others, who argue to the same effect, are not uncontroversial and have indeed been criticised (e.g. Braham and van Hees 2010). But, rather than engaging in a discussion about the exact worth of these arguments, we will, for the moment, accept statement 5 above. As we have seen, statement 5

\footnotetext{
11 Of course, this would then create individual moral obligations to coordinate efforts, but these seems already be covered by the moral obligation stated in 2 that we discussed above.
} 
might be true even if Sinnott-Armstrong and Johnson are wrong. We now want to ask what the case of climate change can teach us about the problem of many hands more generally. To do so, we will consider the three different dimensions of the problem of many hands that Bovens (1998: 46-49) refers to: the practical, the normative and the preventive dimension. Our focus in this section will be on responsibility-as-blameworthiness. In the next section, we will discuss the other senses of responsibility in relation to the problem of many hands.

First, the problem of many hands can be conceived as a practical problem. It is often difficult in collective settings to identify and prove who was responsible for what. Especially for outsiders, it is usually very difficult, if not impossible, to know who contributed to, or could have prevented, a certain action, who knew or could have known what, et cetera. So conceived, the problem of many hands is primarily an epistemological problem because the problem of identifying who is responsible for what arises from a lack of knowledge.

This epistemological dimension does not appear to play a large role in the case of climate change. Of course, if we needed to find out how much each citizen in the world contributed causally to global warming, that would be very difficult if not impossible. However, the reasons discussed in the climate change case for why no individual can reasonably be held responsible seem to be of a much more principled nature. This can be seen as follows. Suppose that someone, say an independent observer, had perfect knowledge of who causally contributed to what, could have known what et cetera. If statement 5 is true, as we are assuming, even for this observer it would be impossible to identify someone who was responsible-asblameworthy for climate change.

We might, of course, conclude that this means that simply nobody is responsible. However, the problem of many hands typically seems to refer to those situations in which individual responsibility is obscured, but one feels that this is inappropriate or wrong. This brings us to the second dimension of the problem of many hands, the normative or moral dimension. As Bovens says this dimension "raises the question whether the responsibility of the collectivity, the organisation, can be reduced to the individual responsibilities of discrete functionaries not just in practical but also in moral regard" (Bovens 1998: 47). Bovens suggests that the collective might sometimes be responsible while none of the individuals is responsible. His suggestion is thus that the problem of many hands occurs in the situation in which the collective is responsible but in which, nevertheless, none of the individuals that together constitute the collective is responsible.

The notion of collective responsibility that Bovens is referring to here may be termed 'non-reductive collective responsibility,' i.e. collective responsibility that cannot be reduced to the individual responsibilities of the members of the collective. Several philosophers have indeed argued for the possibility of such non-reductive collective responsibility (e.g. Pettit 2007; Copp 2007; French 1984), although there are also philosophers who believe that collective responsibility is always reductive (e.g. Miller 2010).

Sinnott-Armstrong also seems to rely on the assumption of non-reductive collective responsibility. He argues that "even if individuals have no moral obligation not to waste gas by taking unnecessary Sunday drives just for fun, 
governments still have moral obligations to fight global warming" (SinnottArmstrong 2005: 304). He also maintains that "individual moral obligations do not always follow directly from collective moral obligations" (Sinnott-Armstrong 2005: 287). If we look at responsibility-as-blameworthiness, the sense of responsibility that is most discussed in relation to the problem of many hands, we have seen that it might well be possible that no individual can be properly blamed for climate change. It may, however, be possible that at the same time the government can be properly blamed if it were proper to blame collectives rather than their members.

It appears, however, that it is not necessary to take a position in the debate about collective responsibility to understand the problem of many hands. A closer look at Bovens' arguments reveals that we do not need the idea of collective responsibility to understand why a gap in the distribution of individual responsibility might sometimes be problematic. To do so, we need to look at the third dimension discussed by Bovens: the preventive or control dimension.

According to Bovens, the problem of many hands "frustrates the need for compensation and retribution on the part of victims" (Bovens 1998: 49). Moreover, the "fact that no one can be meaningfully called to account after the event also means ... that no one need feel responsible beforehand" (Bovens 1998: 49), so that future harm cannot be prevented. Both arguments, the lack of retribution and the absence of someone feeling forward-looking responsible, indicate why the occurrence of the problem of many hands is undesirable, but neither of them requires that the collective is responsible while none of the individuals is responsible, as we will see below.

With respect to the first argument, it indeed seems true that if nobody can be properly blamed, retribution is impossible. However, if the collective can properly be held responsible in the case of a problem of many hands, as Bovens suggests, the collective could be properly blamed, and retribution would be possible. Of course, it could be argued that collectives cannot be a proper target of blame, for example because they have no feelings, ${ }^{12}$ but in that case Bovens' suggestion that the collective can be responsible seems be false in the first place. Either way, retribution only seems impossible if neither any individual nor the collective can be properly held responsible-as-blameworthy. This makes Bovens' earlier suggestion that the problem of many hands typically occurs in cases in which the collective is responsible but none of the individuals problematic. Rather than requiring that the collective is responsible, Bovens' first argument about the lack of retribution seems to require that the collective is not responsible.

Bovens' second argument about the lack of forward-looking responsibility seems equally dubious when we consider the climate change case. If we accept SinnottArmstrong's and Johnson's arguments, individuals cannot be reasonably held backward-looking responsible for climate change, as we have seen. Still, on their accounts, individuals have a forward-looking responsibility to strive for collective

\footnotetext{
${ }^{12}$ It might perhaps be argued that the object of our blame do not need to have feelings to be a proper target of blame, as we can blame our computer or the weather. However, responsibility-asblameworthiness is usually believed to presuppose moral agency and the possibility of the blamed agent to adjust his or her behavior in the light of reactive attitudes like blame. This seems to require feelings.
} 
agreements that would effectively abate climate change. Lack of individual backward-looking responsibility therefore does not entail the absence of individual forward-looking responsibility. A somewhat similar argument has been made by one of us in relation to environmental problems more generally: even if some individual citizens are not backward-looking responsible for certain environmental problems, they may still be forward-looking responsible (Nihlén Fahlquist 2009a). This does not imply that we can always be sure that someone will be forwardlooking responsible for any problem and, of course, if a gap occurs with respect to forward-looking responsibility this might be considered a problem. The point only is that it should not be assumed that such problems necessarily occur if there is a gap in the distribution of backward-looking responsibility.

\section{Redefining the Problem of Many Hands}

We have seen that Bovens' suggestion that the problem of many hand occurs if a collective is responsible but none of the individuals in the collective is responsible is a problematic one. Rather than requiring that the collective is responsible, we might want to require that neither the collective nor the individuals are responsible. So rather than embracing Bovens' suggestion we want to propose the following general definition of the problem of many hands:

A problem of many hands occurs if there is a gap in a responsibility distribution in a collective setting that is morally problematic.

This definition retains three main elements on which all authors writing about the problem of many hands cited in the introduction (Thompson, Nissenbaum, Bovens) seem to agree: (1) the problem of many hands occurs in collective settings, in which (2) it is impossible, or at least very difficult, to attribute responsibility to someone, so that there is a gap in the responsibility distribution and (3) this gap is morally problematic.

The main question that is not yet answered by this proposal, and to which we will now turn, is when a gap in a responsibility distribution can be called morally problematic. To answer this question, we need to look at the reasons why we attribute responsibility in the first place. As we saw above, in the philosophical literature, responsibility is often understood in terms of reactive attitudes. The idea is that an agent, when properly held responsible, deservers a certain treatment. If one focuses on bad, rather than good, consequences, as is often done in discussions about responsibility, the goal or function of attributing responsibility is retribution.

However, retribution is not the only possible function of attributing responsibility. Another often mentioned function, and according to some consequentialists the only legitimate goal, is what might be called efficacy in achieving a desirable goal or solving a social problem. Some distributions of responsibility are more efficacious in attainting certain desirable ends than others. Apart from retribution and efficacy, responsibility might also serve such functions as maintaining or restoring the moral community, doing justice to victims, putting a bad situation right or preventing harm. 
Table 1 Relationship between senses of responsibility and typical functions of attributing responsibility

\begin{tabular}{ll}
\hline Sense of responsibility & $\begin{array}{l}\text { Function of attributing } \\
\text { responsibility }\end{array}$ \\
\hline $\begin{array}{l}\text { Backward-looking } \\
\text { Responsibility-as-blameworthiness }\end{array}$ & $\begin{array}{l}\text { Retribution } \\
\text { Mesponsibility-as-accountability }\end{array}$ \\
$\begin{array}{l}\text { Maintaining moral } \\
\text { community }\end{array}$ \\
Responsibility-as-liability & Justice to victims \\
Forward-looking & \\
Responsibility-as-obligation & Efficacy \\
Responsibility-as-virtue & Due care to others
\end{tabular}

Depending on the ethical theory one adopts, one is likely to consider certain functions of responsibility attributions more legitimate or important than others. Deontologists, for example, will tend to emphasize retribution while consequentialists would focus on efficacy. One of us has, in an earlier paper, discussed three perspectives on attributing responsibility in engineering, the merit-based, the rightsbased and the consequentialist perspective (Doorn forthcoming).

The function of a responsibility distribution does, however, not just depend on one's ethical theory or perspective but also on the sense of responsibility focused on. Responsibility-as-blameworthiness is, for example, typically connected to retribution. Forward-looking responsibility-as-obligation will often be connected to efficacy. Liability often seems to be motivated by the desire to do justice to (potential) victims, although preventing harm is also sometimes mentioned as a goal (e.g. Zandvoort 2000). Accountability may be connected to restoring or maintaining the moral community (cf. Kutz 2000). ${ }^{13}$ Finally, responsibility-as-virtue might be assumed to express due care to others as suggested earlier. Table 1 summarizes these relations.

Given the discussed functions of attributing responsibility, one might wonder how it would be possible to have a problematic gap in the distribution of responsibility. If we want retribution, we just hold someone blameworthy; if we want efficacy, we just choose that distribution of responsibility that is likely to be most efficacious for attaining a certain goal. The reasons why, nevertheless, gaps can occur is that we usually want a responsibility distribution not just to attain the functions mentioned in Table 1, but that we also want it to be fair or reasonable. We will call this the fairness requirement for distributing responsibility.

One way to fill out the fairness requirements is to pose that we only want to hold agents responsible for a certain outcome if certain reasonable conditions are met. We have discussed five of such conditions earlier in this paper: capacity, causality, knowledge, freedom and wrong-doing. These are the typical conditions for responsibility-as-blameworthiness and we have argued that, on such a set of

\footnotetext{
${ }^{13}$ It does so in two ways. First, by holding someone accountable we confirm that that agent is a moral agent and, hence, part of the moral community. Second, by holding someone accountable for an undesirable action or outcome, we confirm or restore the moral rules on basis of which an outcome or action is deemed undesirable and which ties the moral community together.
} 
conditions, it might very well be possible that no one can be fairly held blameworthy for certain collective harms. In as far as retribution for such harms is considered morally important, this gap might be considered morally problematic.

For other senses of responsibility, other conditions than the five just mentioned might be important. One of us has, for example, argued that responsibility-asaccountability is based on conditions of capacity, causality and wrong-doing (Van de Poel forthcoming). Some believe that responsibility-as-liability requires blameworthiness (e.g. Hart 1968) while others deny this connection (e.g. Davis forthcoming). Forward-looking responsibility-as-obligation may depend on people's capacity to contribute to the solution of a problem or to bring about a certain situation, but also on past causal contributions or backward-looking moral responsibility (Miller 2001). ${ }^{14}$

As this brief discussion illustrates, the different senses of responsibility are not completely mutually independent. Typically, different perspectives on responsibility-such as the merit-based, the rights-based and the consequentialist perspective-emphasize different senses of responsibility, and construct different relations between the different senses (Doorn forthcoming). Despite such relations between the different senses of responsibility, the discussion of the climate change case has shown that the senses are often independent enough to make it possible that no person can be reasonably held responsible-as-blameworthy for a certain problem while, at the same time, at least some people may be reasonably ascribed a forwardlooking responsibility-as-obligation for helping to prevent the same problem in the future.

Table 1 then teaches us two important lessons with respect to the problem of many hands. First, whether there is a gap in a responsibility distribution depends on the sense of responsibility one focuses on and on the exact way the fairness requirement is understood for that sense of responsibility. Second, the subsequent judgement whether such a gap is problematic will depend on what is seen as the main function of attributing that sense of responsibility.

\section{Conclusions}

The problem of many hands is usually understood as the difficulty, or even impossibility, of holding someone fairly responsible for an undesirable collective outcome. Our proposed reformulation of the problem of many hands, in terms of a problematic gap in the distribution of responsibility, fits this general characterisation, but it is more precise in two respects. First, it restricts the problem of many hands to problematic gaps; second, it is so formulated that it can apply to both backward-looking and forward-looking responsibility and the various more specific senses of responsibility. We have further suggested that whether a gap occurs in a responsibility distribution, and whether such a gap is problematic, depends both on one's perspective on responsibility (e.g. merit-based, rights-based,

\footnotetext{
14 There is now a whole discussion about how responsibility for preventing and dealing with the effects of climate change is to be distributed (e.g. Shue 1993; Caney 2005; Miller 2009).
} 
or consequentialist) and on the exact sense of responsibility (accountability, blameworthiness, liability, obligation or virtue) focused on.

Acknowledgments This paper was written as part of the research program 'Moral Responsibility in R\&D Networks', which is supported by the Netherlands Organization for Scientific Research (NWO) under grant number 360-20-160.

Open Access This article is distributed under the terms of the Creative Commons Attribution Noncommercial License which permits any noncommercial use, distribution, and reproduction in any medium, provided the original author(s) and source are credited.

\section{References}

Aristotle. (2000). Nicomachean Ethics (Cambridge texts in the history of philosophy). Cambridge, UK; New York: Cambridge University Press.

Audi, R. (1991). Responsible action and virtuous character. Ethics, 101(2), 304-321.

Austin, J. L. (1956-1957). A plea for excuses. Proceedings of the Aristotelian Society, 57(1-30).

Bovens, M. (1998). The quest for responsibility. Accountability and citizenship in complex organisations. Cambridge: Cambridge University Press.

Braham, M., \& van Hees, M. (2010). An anatomy of moral responsibility. Manuscript. Retrieved from: http://www.rug.nl/staff/martin.van.hees/MoralAnatomy.pdf.

Caney, S. (2005). Cosmopolitan justice, responsibility, and climate change. Leiden Journal of International Law, 18(4), 747-775.

Copp, D. (2006). Ought' implies 'can, blameworthiness and alternate possibilitites. In D. Widerker \& M. McKenna (Eds.), Moral responsibility and alternative possibilities. Aldershot: Ashgate.

Copp, D. (2007). The collective moral autonomy thesis. Journal of Social Philosophy, 38(3), 369-388. doi:10.1111/j.1467-9833.2007.00386.x.

Davis M. (forthcoming). "Ain't no one here but us social forces": Constructing the professional responsibility of engineers. Science and Engineering Ethics, 1-22. doi:10.1007/s11948-010-9225-3.

Doorn, N. (forthcoming). Responsibility ascriptions in technology development and engineering: Three perspectives. Science and Engineering Ethics, 1-22. doi:10.1007/s11948-009-9189-3.

Frankfurt, H. (1969). Alternate possibilities and moral responsibility. Journal of Philosophy, 66, 829-839.

French, P. A. (1984). Collective and corporate responsibility. New York: Columbia University Press.

French, P. A., Wettstein, H. K., \& Fischer, J. M. (Eds.). (2005). Free will and moral responsibility (Midwest studies in philosophy). Malden: Blackwell.

Ginet, C. (2006). In defense of the principle of alternate possibilities: why i don't find Frankfurt's argument convincing. In D. Widerker \& M. McKenna (Eds.), Moral responsibility and alternative possibilities essays on the importance of alternative possibilities. Alsdershot: Ashgate.

Goodin, R. E. (1995). Utilitarianism as a public philosophy. Cambridge: Cambridge University Press.

Hart, H. L. A. (1968). Punishment and responsibility: Essays in the philosophy of law. Oxford: Clarendon Press.

Hart, H. L. A., \& Honoré, T. (1985). Causation in the law (2nd ed.). Oxford: Clarendon Press.

Hindriks, F. (2009). Corporate responsibility and judgement aggregration. Economics and Philosophy, 25, 161-177.

Honoré, T. (1999). Responsibility and fault. Oxford: Hart.

Jamieson, D. (2010). Climate change, responsibility, and justice. Science and Engineering Ethics, 16(3), 431-445. doi:10.1007/s11948-009-9174-x.

Johnson, B. L. (2003). Ethical obligations in a tragedy of the commons. Environmental Values, 12(3), 271-287.

Johnson, D. G. (2006). Computer systems: Moral entities but not moral agents. Ethics and Information Technology, 8, 195-205.

Kutz, C. (2000). Complicity: Ethics and law for a collective age (Cambridge studies in philosophy and law). Cambridge; New York: Cambridge University Press.

Mackie, J. L. (1980). The cement of the universe. A study of causation. Oxford: Oxford Univeristy Press. 
Miller, D. (2001). Distributing responsibilities. The Journal of Political Philosophy, 9(4), 453-471.

Miller, S. (2007). Against the collective moral autonomy thesis. Journal of Social Philosophy, 38(3), 389-409. doi:10.1111/j.1467-9833.2007.00387.x.

Miller, D. (2009). Global justice and climate change: How should responsibilities be distributed? The Tanner Lectures on Human Values, 28, 119-156.

Miller, S. (2010). The moral foundations of social institutions: A philosophical study. New York: Cambridge University Press.

Miller, S. (forthcoming). Collective responsibility, epistemic action and climate change. In N. Vincent, I. Van de Poel, \& J. Van den Hoven (Eds.), Moral responsibility. Beyond free will and determinism. Dordrecht: Springer.

Nihlén Fahlquist, J. (2006). Responsibility ascriptions and vision zero. Accident Analysis and Prevention, 38, 1113-1118.

Nihlén Fahlquist, J. (2009a). Moral responsibility for environmental problems-individual or institutional? Journal of Agricultural and Environmental Ethics, 22(2), 109-124. doi:10.1007/ s10806-008-9134-5.

Nihlén Fahlquist, J. (2009b). The problem of many hands and responsibility as the virtue of care. In Managing in critical times-philosophical responses to organisational turbulence proceedings, 2009.

Nissenbaum, H. (1996). Accountability in a computerized society. Science and Engineering Ethics, 2(1), $25-42$.

Pettit, P. (2007). Responsibility incorporated. Ethics, 117, 171-201.

Shapiro, P. (2006). Moral agency in other animals. Theoretical Medicine and Bioethics, 27, 357-373.

Shue, H. (1993). Subsistence emissions and luxury emissions. Law \& Policy, 15(1), 39-60. doi: 10.1111/j.1467-9930.1993.tb00093.x.

Sinnott-Armstrong, W. (2005). It's not my fault: Global warming and individual moral obligations. In W. Sinnott-Armstrong \& R. B. Howarth (Eds.), Perspectives on climate change science, economics, politics, ethics (pp. 285-307). Amsterdam: Elsevier/JAI.

Smiley, M. (1992). Moral responsibility and the boundaries of community: Power and accountability from a pragmatic point of view. Chicago: Chicago University Press.

Strawson, P. (1962). Freedom and resentment. Proceedings of the British Academy, 48, 187-211.

Thompson, D. F. (1980). Moral responsibility and public officials: The problem of many hands. American Political Science Review, 74(4), 905-916.

Van de Poel, I. (forthcoming). The relation between forward-looking and backward-looking responsibility. In N. Vincent, I. Van de Poel, \& J. Van den Hoven (Eds.), Moral responsibility. Beyond free will and determinism. Dordrecht: Springer.

Van Inwagen, P. (1983). An essay on free will. Oxford: Clarendon Press.

Vanderheiden, S. (forthcoming). Climate change and collective responsibility. In N. Vincent, I. Van de Poel, \& J. Van den Hoven (Eds.), Moral responsibility. Beyond free will and determinism. Dordrecht: Springer.

Vedder, A. (2001). Accountability of internet access and service providers: Strict liability entering ethics? Ethics and Information Technology, 3(1), 67-74.

Wagenaar, W. A., \& Groenewegen, J. (1987). Accidents at sea: Multiple causes and impossible consequences. International Journal of Man-Machine Studies, 27, 587-598.

Wallace, R. J. (1994). Responsibility and the moral sentiments. Cambridge; MA: Harvard University Press.

Widerker, D. (2005) Blameworthiness, non-robust alternatives and the principle of alternative expectations. In: French, P.A. \& Wettstein, H. K. (Eds.), Fischer, J. M. (guest ed) Free will and moral responsibility. Midwest studies in philosophy Blackwell, Malden.

Widerker, D., \& McKenna, M. (2006). Moral responsibility and alternative possibilities: Essays on the importance of alternative possibilities. Aldershot: Ashgate.

Williams, B. (1999). Moral Luck. Philosophical papers 1973-1980. Cambridge: Cambridge University Press.

Zandvoort, H. (2000). Codes of conduct, the law, and technological design and development. In P. Kroes, \& A. Meijers (Eds.), The empirical turn in the philosophy of technology (Vol. 20, pp. 193-205, Reserach in philosophy and technology). Amsterdam etc.: JAI (Elsevier). 